\title{
Acesso ao Ensino Superior: estudo de CASO SOBRE CARACTERÍSTICAS DE ALUNOS DO ENSINO SUPERIOR PRIVADO*
}

\author{
Antonio Alberto da Silva Monteiro de Freitas**
}

RESUMO

A questão central que orienta o fluxo desta investigação relaciona-se com o estudo do perfil socioeconômico e cultural dos estudantes da Faculdade Social da Bahia (FSBA), num contexto de expansão do ensino superior e de acesso a este nível de ensino. Com efeito, procurou-se traçar o perfil desses alunos fazendo um estudo comparativo com os da Universidade Federal da Bahia (UFBA), o Nordeste e o Brasil, a partir de algumas variáveis demográficas como idade, cor, sexo, renda, escolaridade dos pais, escola básica de origem e colégio do ensino médio, analisando comparativamente o perfil dos alunos em relação aos turnos e aos cursos da FSBA e verificar o efeito dessas variáveis sobre o desempenho desses mesmos estudantes através do exame dos resultados do vestibular e o rendimento no curso.

Palavras-Chave: acesso ao ensino superior, ensino superior privado, ensino superior público, características do aluno.

\section{INTRODUÇÃO}

A Bahia tem despontado no cenário nacional como um dos estados que mais tem expandido o ensino superior, fruto de um processo de modernização e crescimento de suas atividades econômicas. Dados do MEC (2002) indicam que existiam 69 instituições de ensino superior em todo o Estado, entre as quais 64 pertenciam ao setor privado.

* Texto recebido em 16/11/2004 e aprovado em 14/12/2004.

** Mestre em Educação pela Universidade Federal da Bahia - UFBA. Vice-diretor geral da Faculdade Social da Bahia. [E-mail: aalberto@fsba.edu.br] 
A demanda pela criação de instituições de ensino superior privadas na Bahia explica-se, sobretudo, pela relativa autonomia que a Lei de Diretrizes e Bases da Educação (Lei no 9.394/96) concede aos estados para a implantação de seus sistemas de ensino superior e para a criação de novos cursos e, por sua vez, o surgimento desses novos cursos nas IESPs explica-se, também, pela demanda reprimida para a educação superior no país como um todo, não atendida pelo setor público em função do crescente número de alunos que conclui o ensino médio e à quase estagnação da universidade pública em termos de aumento da oferta de vagas.

As análises a respeito do ensino superior privado, quando ocorrem, estão voltadas para aspectos de expansão, infra-estrutura e mercado de trabalho, assim como para expectativa de lucro que essa atividade pode proporcionar. Ao que parece, tem sido concedida pouca atenção às características do alunado, nomeadamente das faculdades particulares. Esse desconhecimento do perfil dos alunos tem levado as instituições de ensino superior a cometerem graves erros na formulação de políticas e programas de gestão, assim como na concepção de seus currículos escolares.

Com a Lei de no 9.394/96, as instituições de ensino superior privado obtiveram maior autonomia para selecionarem seus alunos. Com a flexibilização dos processos seletivos há uma nova configuração do alunado que chega ao ensino superior, a qual precisa, mais do que nunca, ser estudada e analisada para que se possa assegurar a qualidade dos serviços na rede privada. Diante do crescimento da rede privada em Salvador e diante da flexibilização dos processos seletivos para onde afluem alunos, muitos dos quais não conseguiram ingressar nas universidades públicas, sobretudo na UFBA e na Uneb, o primeiro passo é saber quem são esses alunos, tanto em relação às suas condições de vida como à sua situação de aprendizagem, para em seguida implementar políticas pedagógicas centradas no processo formativo, com ênfase na qualidade e nosprojetos adequados de financiamento estudantil, visando reduzir as dificuldades apresentadas pelos que ingressam no ensino superior e, conseqüentemente, assegurar a permanência desses alunos nos cursos.

$\mathrm{O}$ acesso desigual dos grupos sociais ao ensino superior e o desempenho de um estudante nesse nível de ensino são resultantes de uma extensa gama de fatores relativos ao ambiente familiar, ao status socioeconômico, à formação do aluno, ao tipo de escola freqüentada 
anteriormente, assim como à própria personalidade do aluno. Esse é um tema que vem ocupando pesquisadores há algumas décadas e muitas interpretações têm sido formuladas para compreender a interferência dos sistemas de ensino na reprodução das desigualdades sociais (Rosemberg, 1989; Halsenbalg, 1991; Furlani, 1998) e que se constitui eixo básico dessas nossas reflexões.

Os trabalhos de Halsenbalg (1991) analisam as desigualdades sociais no Brasil ancoradas, em grande parte, em diferenças sociais. Em linhas gerais, elas indicam que a cor opera como um elemento que afeta o desempenho dos indivíduos negros, nos diversos setores da vida social. As análises desses trabalhos concluem que negros e mulatos têm níveis de escolaridade inferiores aos dos brancos da mesma origem social e que eles têm sido excluídos da escola em todos os níveis, desde os anos mais remotos de sua escolarização.

A pesquisa de Queiroz (2001) discute raça, gênero e educação superior, mostrando que, no campo educacional, a condição racial do estudante, como outras categorias de exclusão, irá determinar seu destino escolar. Para a autora, o destino de mulatos e negros constrói-se, paulatinamente, desde os momentos mais remotos da escolarização, em geral através de escolas públicas de baixa qualificação. Os poucos negros que chegam à universidade, segundo a autora, vêm de uma formação escolar precária dada a sua classe social modesta e isso os leva a ingressar nas carreiras menos concorridas e de menor status social, normalmente as humanidades, que, em geral, estão associadas às ocupações de baixa remuneração.

Também o gênero representa uma dimensão importante na estruturação das desigualdades sociais. Ao longo de sua história, as mulheres tiveram sua presença limitada ao mundo doméstico e, apesar de profundos e significativos avanços no que se refere à ocupação de espaços no mercado de trabalho, ainda se percebem, hoje, resquícios dos antigos modelos excludentes das mulheres traduzidos e evidenciados na ordem social muito repressiva para o sexo feminino. Recente estudo sobre articulação de gênero, do autor Henriques (UNESCO, 2002), revela que as mulheres precisam de uma vantagem de cinco anos de escolaridade para alcançar a mesma probabilidade que os homens têm de obter um emprego no setor formal. Para as mulheres negras alcançarem os mesmos padrões das mulheres brancas com quatro a sete anos de estudos, 
elas precisam de mais quatro anos de instrução, ou seja, de oito a onze anos de estudos.

$\mathrm{O}$ vestibular tem sido alvo privilegiado para essa análise. Barroso e Mello (1975) examinam as variáveis que afetam o desempenho dos estudantes no vestibular e apontam os mesmos fatores já citados que determinam esse desempenho, como sexo, nível socioeconômico da família, escolaridade dos pais, vida escolar anterior do candidato e local de residência. As análises feitas nessa direção indicam que os determinantes econômicos, assim como outros elementos como a cor, o gênero e o status, são responsáveis pela exclusão de considerável parcela da população da oportunidade de acesso ao ensino superior no Brasil.

As pesquisas até então realizadas no Brasil sobre as características do aluno na rede privada de ensino têm mostrado que esses estudantes combinam deficiência acadêmica (os menos preparados em termos escolares) com carências socioeconômicas (os de menor renda familiar) e limitações para a dedicação plena aos estudos, uma vez que são jovens que conciliam estudo e trabalho até com possibilidade de poderem freqüentar um curso superior. Fenômeno contrário ocorreria no setor público de ensino superior (SAMPAIO, 2000, p. 249).

Há muitas verdades e muitos mitos em constatações tão genéricas como essas. O fato é que democratização e elitização são elementos presentes nas instituições públicas e privadas de ensino superior, tratandose de um assunto de grande complexidade, porque envolve outros fatores além daqueles que vêm sendo apresentados e discutidos. A confluência desses múltiplos fatores constitui, portanto, um campo muito valioso para diagnosticar a real situação do corpo discente das instituições privadas e, diante dessa realidade, implementar políticas e programas adequados de planejamento e gestão escolar.

Desconhecer a cadeia de relações entre acesso ao ensino superior, rendimento escolar e sua multiplicidade de outras variáveis pode implicar em decisões inadequadas por parte das instituições no tratamento desse tema. Portanto é de extrema importância conhecer a clientela que está indo para as instituições privadas, conhecer as variáveis que interferem no desempenho escolar, para, diante disso, determinar os projetos acadêmicos, as propostas curriculares e os investimentos a serem feitos, tendo sempre como objetivo a "aprendizagem e acompanhamento, passo a passo, do educando, na sua trajetória de construção do conhecimento" (HoFman, 1993, p. 18). 
Em linhas gerais procurou-se delimitar o trabalho buscando-se responder às seguintes questões: 1) Qual é o perfil socioeconômico e cultural dos alunos da Faculdade Social da Bahia? 2) Existem diferenças entre os estudantes das instituições de ensino superior (IES) privadas e os estudantes das instituições federais de ensino superior (IFES)? 3) Há diferença de perfis dos estudantes da FSBA em relação aos cursos e aos turnos? 4) Haveria alguma influência da idade dos alunos no resultado do vestibular e no rendimento dos cursos? 5) A cor dos alunos teria alguma relação com o rendimento dos alunos no vestibular e nos cursos? 6) O gênero também teria alguma relação com o aproveitamento no vestibular e nos cursos? 7) O rendimento dos alunos sofre alguma influência da renda familiar? 8) Qual é o efeito da escolaridade dos pais sobre o rendimento dos alunos? 9) Qual é a interferência da origem da escola de ensino médio sobre o rendimento do aluno?

\section{O CASO DA FACULDADE SOCIAL DA BAHIA-FSBA}

Este trabalho foi tratado metodologicamente como estudo de caso e utilizou a base de dados do universo dos estudantes ingressos na FSBA no ano de 2002, nos cursos de Administração em Recursos Humanos, Administração em Gestão de Negócios, Jornalismo, Educação Física e Normal Superior. A base foi construída a partir da aplicação de um questionário com perguntas fechadas. As análises estatísticas foram processadas através do programa SPSS e, em seguida, analisadas as seguintes variáveis: idade, raça, sexo, renda familiar, escolaridade dos pais, tipo de escola média freqüentada pelo aluno, escore global no vestibular e rendimento médio no curso de graduação.

Os resultados decorrentes da investigação feitas são aqui apresentados de maneira sintética, à luz das principais variáveis selecionadas. Destaca-se entre eles o fato de que a média de idade dos alunos encontra-se na faixa de 24,56 anos, considerando a média dos cursos. Consideramos esta uma média bastante alta decorrente da presença de um número grande de alunos com idade mais elevada, sobretudo nos cursos noturnos, que puxam a média para cima, fato que pode ser comprovado pelo desvio-padrão também relativamente alto $(6,86 \%)$. Constatamos ser esta uma tendência também da UFBA, do Nordeste e do Brasil, o que reforça a tese de que os estudantes brasileiros 
ingressam tarde no ensino superior em decorrência das distorções entre idade e série na educação básica. Esse fenômeno vem contribuindo para que o Brasil tenha uma das mais baixas taxas de escolarização bruta do mundo (relação entre o total de matrículas, independente da idade, e o total da população entre dezoito e vinte e quatro anos). Essa taxa estava no ano 2000 no (atual) nível de $11 \%$, segundo dados do MEC e o resultado é que 53\% dos alunos do ensino superior têm mais de 24 anos (MEC, 2000, p. 11).

O curso Normal Superior da FSBA é o que incorpora estudantes com médias de idade mais altas (31,67 no turno matutino e 31,34 no turno noturno), seguido do curso de Administração em Recursos Humanos que apresenta médias de idade dos alunos também altas (25,92 no turno matutino e 26,24 no turno noturno).

São nesses cursos que se verifica maior distorção de idade, o que significa que os alunos interromperam sua formação, voltando a estudar muitos anos depois. É provável que os alunos do curso normal superior tenham voltado a estudar mais tarde por conta da exigência da LDB, que aponta a necessidade dos professores que lecionam na educação infantil e nas séries iniciais do ensino fundamental possuírem o nível superior. Na Bahia, 78\% desses professores não atendem ainda a esta recomendação legal. Já no curso de Administração em Recursos Humanos, a média alta de idade pode justificar-se pela baixa concorrência desse curso ( 0,48 no matutino e 1,34 no noturno), o que pode ter atraído alunos que também interromperam sua formação e que se acharam menos preparados para ingressarem, muitos anos mais tarde, no ensino superior, em cursos mais concorridos.

A menor média de idade está no curso de Administração matutino $(20,9)$, no curso de Jornalismo vespertino $(21,7)$ e no curso de Educação Física matutino $(21,9)$. Esses cursos são constituídos por alunos mais jovens que deram seqüência aos estudos do ensino médio quase que de imediato e que se sentiram mais preparados para enfrentarem cursos mais concorridos - Educação Física $(3,70)$ e Jornalismo $(2,23)$. Em relação aos turnos, há também diferença de idade. A média de idade dos alunos dos cursos diurnos da FSBA é 24,2 e a média de idade dos alunos dos turnos noturnos é 25,9.

A diferença não é muito grande, mas os números demonstram a presença de alunos com maior idade nos cursos noturnos, realidade decorrente da construção histórica dos trabalhadores que, normalmente, 
são chefes de família e necessitam trabalhar durante o dia, e para os quais a urgência de entrada cedo no mercado de trabalho condiciona o prosseguimento de estudos em outro turno que não seja o noturno.

Como veremos nos próximos itens, o nível socioeconômico das famílias de grande parte dos estudantes desse curso encontram-se na camada inferior, fator que talvez explique o seu ingresso mais tardio no ensino superior

Os alunos brancos e morenos da FSBA são majoritários, já que em todos os cursos o porcentual dessas duas categorias é sempre superior a $80 \%$. Negros e mulatos são minoria e são pouco expressivos, embora haja uma presença considerável de negros na FSBA $(12,86 \%)$, sobretudo nos cursos de Administração em Gestão de Negócios (matutino, 16\%, e noturno, 14,3\%) e no curso de Educação Física (matutino, 15,7\%, e noturno, 15,4\%). Esse número é superior ao encontrado por Queiroz (2001) na UFBA $(8,90 \%)$ e isso sugere maior facilidade de acesso ao ensino superior privado em relação ao acesso a uma universidade pública, onde há maior competitividade e cursos de mais alto prestígio em relação aos da FSBA. Os negros estão mais concentrados nos cursos noturnos de Administração em Recursos Humanos $(9,1 \%)$, no curso de Jornalismo noturno $(12,9 \%)$ e no Normal Superior $(11,4 \%)$. Nos cursos de Administração emGestão de Negócios e Educação Física é maior o porcentual de negros que estudam durante o dia.

Os dados mostram que brancos e morenos são majoritários na FSBA e que há ainda um porcentual muito baixo de negros e mulatos que têm acesso ao ensino superior, sobretudo em um estado como o nosso, onde a maioria da população é constituída de negros e de mulatos. Cursos como Administração em Recursos Humanos (matutino, 4,2\% de negros), Administração em Gestão de Negócios (noturno, zero por centro de mulatos) e Educação Física (1,2\% de mulatos) estão entre aqueles que representaram uma barreira para entrada de negros.

Estes dados reforçam a tese de alguns autores (Hasembalg, 1997; Henriques, 2002; Queiroz, 2001; Vieira, 2002) que mostram como o preconceito e a discriminação tornam o acesso diferenciado da população negra à universidade e quanto mais altos os níveis de ensino, maior é a exclusão de parcelas consideráveis da população negra.

As mulheres na FSBA representam 50,1\% do total do alunado, enquanto os homens representam 49,9\%. É uma tendência também da 
UFBA, do Nordeste e do Brasil, o que reforça a tese de alguns autores mais contemporâneos que demonstram que, apesar de a constituição do grupo macro apresentar um equilíbrio entre homens e mulheres, o que se pode observar é que houve, nas últimas décadas, uma incorporação de grande contingente de mulheres que estão tendo acesso ao ensino superior, superando inclusive a participação masculina (LiMA, 1996; SANTANA, 1997; Passos, 1999).

No curso de Administração em Recursos Humanos há uma predominância de mulheres tanto de manhã $(75 \%)$ como à noite $(60,6 \%)$, assim como no curso de Jornalismo (70,9\%, vespertino, e 56,8\%, noturno) e no curso Normal Superior, onde a maioria absoluta é de mulheres (95,7\%, matutino, e 94,3\%, noturno). Já no curso de Administração em Gestão de Negócios, matutino e noturno, há uma preponderância de homens (64\% e $74,3 \%$, respectivamente), assim como nos cursos de Educação Física, matutino e noturno (65,3\% e 80,8\%, respectivamente).

A predominância de mulheres nos cursos de Jornalismo e Administração em Recursos Humanos demonstra que nem sempre as mulheres encontram-se nos cursos de menor prestígio como normalmente se defende na literatura, embora na análise da distribuição por curso verifica-se procura diferencial de alguns cursos por rapazes e moças. Nesse caso, chama a atenção o curso Normal Superior, inserido nas Ciências classificadas como Humanas, incluindo área de Educação, que é composto por uma maioria esmagadora de mulheres (95\% de mulheres para 5\% de homens). É um curso voltado para o exercício do magistério, o que reitera a idéia de que as "escolhas" realizadas pela mulher trazem subjacente um processo de socialização que a leva a "gostar" de profissões "adequadas" ao seu sexo, cujo exercício não lhe impõe maiores barreiras. São as "vantagens" que se oferecem às mulheres trabalhadoras para compensar desvantagens de remuneração baixa, do desprestígio social e do caráter discriminador da sociedade capitalista (FurLANI, 1998, p. 66).

Sintetizando, encontra-se um maior equilíbrio dos dois sexos no universo dos alunos da Faculdade Social da Bahia em carreiras que apresentam maior demanda, como é o caso de Administração e Jornalismo, o que pode indicar uma mudança social e histórica na procura por profissões, em direção à superação de preconceitos e discriminações.

Já o sexo feminino predomina ainda em cursos das áreas das Ciências Humanas e voltadas para a formação de professores, como atestam os estudos nessa área. 
Dos alunos da FSBA, 25,7\% têm renda familiar de 1 a 4,9 salários mínimos, um porcentual maior que a UFBA, 20,1\% (QUEIROZ, 2001), enquanto $28 \%$ têm renda entre 5 a 9,9 salários mínimos, perfazendo um total de 53,7\% de alunos com renda abaixo de dez salários mínimos. Apenas 15,3\% dos alunos da FSBA têm renda superior a 20 salários mínimos, enquanto que há uma frequiência maior na UFBA nesse extremo superior, 26,9\% (QUEIROz, 2001). No extremo inferior, até 4,9 salários mínimos, há uma frequiência maior na FSBA de estudantes com renda familiar mais baixa, $25,7 \%$, em relação à UFBA, 20,1\%, embora essa diferença seja menor que o extremo superior.

Os cursos da FSBA que têm alunos de maior poder aquisitivo são os de Administração em Gestão de Negócios, noturno, de Jornalismo vespertino e Educação Física matutino, já que esses cursos têm mais de $20 \%$ de alunos com renda superior a vinte salários mínimos. Chama a atenção o elevado número de alunos do curso de Administração em Gestão de Negócios noturno que se encontra nessa faixa de renda (22,9\%), embora, paradoxalmente, seja maior o número de alunos nesse curso que tem renda inferior a cinco salários mínimos $(34,2 \%)$. Os cursos que têm alunos mais pobres são o de Administração em Recursos Humanos, Jornalismo noturno e Normal Superior, os quais têm grandes porcentuais de alunos com renda abaixo de cinco salários $(41,7 \%$, Administração em Recursos Humanos matutino; 42,9\%, Normal Superior noturno e 25,8\%, Jornalismo noturno).

Nos cursos noturnos de Gestão de Negócios e de Educação Física, os estudantes têm renda familiar mais elevada do que os dos turnos matutino e vespertino.

Em relação aos cursos de Administração em Recursos Humanos e Normal Superior, verificaram-se os mais baixos níveis de renda. Ao se cruzar as variáveis renda e sexo, observa-se que se trata de cursos constituídos, na sua maioria, por mulheres, o que reforça a hipótese de que as mulheres têm renda mais baixa do que a dos homens. As estatísticas dos cursos de Administração em Recursos Humanos e Gestão de Negócios matutino foram prejudicados pelo alto número de alunos que não declarou a renda $(20,8 \%$ e $24 \%$, respectivamente).

A pesquisa mostra claramente que os alunos da FSBA vieram, na sua maioria, da rede privada, de escolas de menor prestígio. A única exceção é o curso Normal Superior, cujo porcentual de alunos oriundos da rede pública é maior do que o da rede privada $(69,6 \%$ matutino e 
54,3\% noturno). Há também um equilíbrio maior entre o público e o privado no Curso de Administração em Recursos Humanos. Ao se comparar essa variável com a variável renda, verifica-se que são os dois cursos constituídos por alunos mais pobres justamente porque vieram da rede pública de ensino.

Os cursos da FSBA - que atraíram mais alunos do Instituto Social da Bahia-ISBA (16,60\% em relação a outros colégios) - foram os cursos de Administração em Gestão de Negócios e Jornalismo, considerados cursos de médio prestígio, enquanto os outros cursos são constituídos, na sua maioria, por alunos oriundos de outros colégios $(83,40 \%)$. Esses alunos de outros colégios também freqüentaram, na sua maioria, o ensino médio e, ao contrário, é reduzido o contingente oriundo de cursos profissionalizantes.

Em relação ao rendimento no vestibular, o curso da FSBA que apresentou melhor resultado foi o de Jornalismo, cuja média global no escore do vestibular foi de 63,92. O curso que se saiu pior no vestibular foi o de Administração em Recursos Humanos com escore médio de 56,60. Já no rendimento no curso, ao final do primeiro semestre, foi o curso Normal Superior o que teve melhor rendimento médio $(8,62)$. Também foi esse curso que teve o escore máximo de rendimento no curso $(9,50)$. O pior curso foi o de Educação Física que teve rendimento médio de 6,56. O coeficiente de correlação para idade $x$ escore no vestibular indica que, na maior parte dos cursos, essas duas variáveis estão negativamente correlacionadas, ou seja, quanto menor é a idade, maior é o escore no vestibular. Os mais jovens, portanto, se saíram melhor no vestibular, enquanto no rendimento no curso essa tendência desaparece, já que a correlação é positiva, ou seja, quanto mais idade maior é o rendimento. No entanto, essa tendência é bastante fraca e, de modo geral, a influência da idade no rendimento, tanto no vestibular quanto no curso, é pequena e pouco significativa. A correlação mais alta encontrase no curso de Administração em Recursos Humanos (0,38), embora com efeito negativo, ou seja, alunos com menor idade obtiveram maior escore no vestibular.

Acredita-se que alunos mais jovens saíram-se melhor no vestibular porque praticamente não interromperam sua formação e se encontravam mais atualizados do que os mais velhos, os quais voltaram a estudar depois de alguns anos, manifestando maiores dificuldades. Já os mais velhos demonstraram mais responsabilidade nos estudos e obtiveram 
melhor rendimento. $\mathrm{O}$ que permite refletir sobre a importância e necessidade de se pensar e pôr em prática novas formas de seleção para ingresso.

As mulheres da Faculdade Social da Bahia, praticamente de todos os cursos, tiveram melhor desempenho no vestibular e, do mesmo modo, também foram elas que obtiveram melhor rendimento nos cursos. $\mathrm{O}$ curso Normal Superior foi prejudicado pelo pequeno número de alunos homens que freqüentam esse curso (95,7\% são mulheres e 4,3\% são homens - Banco de Dados da FSBA-2002). Conforme dados da Secretaria Geral da Instituição, o aluno do Normal Superior que obteve a bolsa de excelência acadêmica por ter obtido a maior média geral durante o primeiro semestre foi do gênero masculino, o que fez com que houvesse maior associação entre os homens e o rendimento escolar nesse curso. A análise evidenciou que tanto na situação do vestibular, caracterizado pela competição e pela disputa, quanto no desempenho no curso, as mulheres apresentam melhor rendimento do que os homens, refletindo sua melhor escolarização durante o ensino médio e uma dedicação e disciplina maiores no curso de graduação, encarando os estudos com mais responsabilidade. Mulatos e negros também demonstraram bom nível de aprendizagem nos cursos, o que evidencia, para esse estrato da população, a importância de se fazer um curso de nível superior com êxito, já que ele representa alguma possibilidade de ascensão social.

$\mathrm{O}$ exame do desempenho no vestibular, considerando o tipo de escola freqüentada no ensino médio, indicou que os estudantes de todos os cursos, oriundos da escola privada, obtiveram melhor desempenho no vestibular do que as que egressaram da escola pública. No entanto, não se observa o mesmo com relação ao rendimento no curso. A pesquisa revelou que, em praticamente todos os cursos (Administração em Recursos Humanos, Administração em Gestão de Negócios, Jornalismo e Educação Física) foram os alunos oriundos da escola pública que obtiveram melhor rendimento no semestre. Isto contraria a idéia de que os alunos que estudaram a maior parte do tempo em escola pública estão fadados ao insucesso por não lhes ter sido oferecida uma preparação adequada, indispensável para a continuação dos estudos. Se isso é também verdade, os dados revelam que é ainda mais importante o esforço construtivo pessoal de cada aluno, o estudo contínuo e diário, o uso da biblioteca, o trabalho persistente, a aprendizagem através da pesquisa e 
a mediação e acompanhamento dos professores, elementos indispensáveis para a aprendizagem significativa dos alunos.

O exame do desempenho dos estudantes por curso, considerando a renda familiar, revela uma associação entre essas duas características. De modo geral, há uma tendência de crescimento do rendimento à medida que a renda também aumenta. Essa tendência de crescimento de rendimento se verifica mais claramente até a faixa de 20 salários mínimos, onde há maior concentração de alunos. Acima dessa faixa, a associação entre rendimento e renda fica prejudicada pela ocorrência de poucos casos nesses níveis, o que torna os dados pouco representativos.

Apesar disso, verifica-se em alguns casos uma clareza da interferência da renda no rendimento da aprendizagem. No curso de Administração em Recursos Humanos, os alunos com renda até cinco salários mínimos tiveram um escore médio no vestibular de 54,84, enquanto os alunos que afirmavam ter renda acima de 20 salários mínimos tiveram um escore global no vestibular de 64,58. Nesse mesmo curso, no rendimento do primeiro semestre, também se verifica alguma correlação entre renda e rendimento escolar: os alunos com renda de até cinco salários mínimos obtiveram a nota média de 6,75 , ao passo que os alunos que tiveram renda na faixa de 10 a 20 salários mínimos obtiveram média de 7,2. No curso de Gestão de Negócios também se verifica essa tendência. No vestibular, os alunos com renda até cinco salários mínimos obtiveram um escore médio de 60,34, enquanto os alunos que têm renda familiar de 20 a 30 salários mínimos obtiveram o escore de 63,22. No curso de Jornalismo, há também correlação positiva entre renda e rendimento observando-se uma tendência de que maior renda significa maior escore: os alunos com renda de até cinco salários mínimos obtiveram o escore de 60,55, no vestibular, e 7,08, no curso, enquanto os alunos com renda de 20 a 30 salários mínimos obtiveram o escore de 67,38 , no vestibular, e 7,9, no curso.

No curso de Educação Física, a interferência da renda dos alunos no rendimento escolar é menor do que nos outros cursos e em alguns momentos observa-se uma tendência de que maior escore está relacionado a alunos de mais baixa renda: alunos com renda de até cinco salários mínimos obtiveram escore de 54,86, no vestibular, e alunos com renda de 20 a 30 salários mínimos obtiveram um escore de 53,87. O Normal Superior segue a tendência dos outros cursos e observa-se que maior renda significa maior rendimento. Acima de 20 salários mínimos, as 
estatísticas também foram prejudicadas pelo número reduzido de casos que se encontram nessa faixa, já que o curso Normal Superior é o curso que apresenta perfis de estudantes mais pobres.

A análise do desempenho dos estudantes no vestibular, considerando a variável escolaridade do pai, demonstra uma tendência de que maior escolaridade paterna significa maior desempenho. Nos cursos de Administração em Recursos Humanos, Educação Física e Normal Superior, a escolaridade do pai tem efeito sobre o desempenho do estudante, mostrando que alunos cujos pais têm escolaridade superior apresentam maiores médias do que aqueles cujo pai não tem nenhuma escolaridade ou tem apenas o ensino fundamental. Já nos cursos de Administração em Gestão de Negócios e Jornalismo, as altas médias dos alunos cujos pais não têm nenhuma escolaridade prejudicaram as estatísticas, uma vez que é muito pequeno o porcentual de pais que se encontra nessa situação (apenas 1,20\% dos pais da FSBA são analfabetos, conforme o banco de dados da FSBA).

O exame da escolaridade do pai sobre o desempenho no curso evidencia que não há muita interferência dessa variável no rendimento, em que muitas vezes a média do rendimento de alunos cujos pais têm baixa escolaridade é maior do que os que têm escolaridade mais elevada. Em relação à escolaridade da mãe, verifica-se um efeito total dessa variável, com o desempenho dos alunos no vestibular demonstrando a importância da mãe na orientação dos estudos dos filhos durante a trajetória escolar, desde as séries iniciais. Já o rendimento nos cursos de graduação, isso não é tão evidente, sugerindo que o sucesso dos alunos na aprendizagem depende muito mais do esforço dos alunos do que da interferência da família.

\section{CONSIDERAÇÕES FINAIS}

Houve, com a realização desta pesquisa, uma tentativa de conhecer um pouco o perfil da clientela das faculdades particulares, nomeadamente da FSBA, e verificar o efeito de algumas variáveis demográficas, como idade, cor, sexo, renda, escolaridade dos pais, escola básica de origem e colégio do ensino médio, sobre o desempenho desses estudantes através do exame dos resultados do vestibular e do rendimento nos cursos (Administração, Jornalismo, Educação Física e Normal Superior). Os 
resultados revelaram dados novos, relevantes e, em alguns casos, surpreendentes, indicando a necessidade de aprofundamento e estudos complementares.

Observou-se que foram as mulheres que obtiveram melhores resultados no vestibular, na maioria dos cursos, quebrando o bloqueio à sua presença nos espaços historicamente reservados aos homens; os estudantes brancos e morenos, da quase totalidade dos cursos, obtiveram maiores escores no vestibular, enquanto os mulatos e negros saíram-se melhor no rendimento dos cursos, mostrando a condição de superação de sua condição social e a certeza de que são capazes de enfrentar um curso de ensino superior com êxito. Os estudantes oriundos da escola privada obtiveram melhor desempenho no vestibular e, ao contrário, foram os alunos que vieram da escola pública que obtiveram melhor rendimento no curso. A vontade de estudar numa faculdade considerada de bom nível, a responsabilidade com que enfrentaram a vida e os estudos, o sonho de terem uma formatura de nível superior fazem desses alunos uns vencedores, superando, em alguns casos, aqueles que tiveram condições de frequientar boas escolas no ensino médio. Na maior parte dos cursos observa-se uma correlação entre renda e rendimento, e alunos com maior renda demonstraram ter um aproveitamento maior tanto no vestibular quanto nos cursos, o que reforça a tese de que o status econômico do indivíduo tem relação direta com os resultados acadêmicos. A associação entre rendimento e escolaridade dos pais é visível nos alunos da Faculdade Social da Bahia, embora ela seja mais forte quando se trata de associação do rendimento dos alunos no vestibular com a escolaridade da mãe.

Esses resultados, se, por um lado, confirmam as teses de que alunos da IES privadas reúnem deficiências acadêmicas e carências socioeconômicas, por outro lado, contribuem para que se desfaçam alguns mitos, principalmente no que se refere ao seu desempenho no curso. Isto significa que a aprendizagem ganha cada vez mais uma dimensão intransferível, construtiva e dinâmica, que pode ser aprimorada com esforço ao longo da trajetória do indivíduo, desde que lhe sejam dadas as mesmas oportunidades. Nesse sentido, fica evidente a necessidade de implantar e determinar projetos pedagógicos e propostas curriculares adequadas à realidade, além de políticas assistenciais aos estudantes nos seus vários níveis, para que eles possam não só ter acesso ao ensino superior, mas, principalmente, permanecer na instituição e concluir o curso 
com as condições adequadas para o seu desenvolvimento com qualidade e para a sua formação como profissionais cidadãos.

\section{ABSTRACT}

The central purpose of this investigation is to identify and analyze the social, economic and cultural profile of the students at the FSBA (Social College of Bahia), in the recent context of expansion and access to higher education. It sights to determine the profile of these students, which is the result of a comparative study made between: 1) they and the ones attending UFBA (Federal University of Bahia); and 2) the reality of the northeast region and the one of the rest of Brazil. Some demographic variables, such as age, color, gender, income, parental schooling, basic education, and comparing them to their school shift (day or night classes), can trace the effects of the development of those students right from their entrance, through the Vestibular exams.

Key Words: access to higher education, private higher education, public higher education, students' profile.

\section{REFERÊNCIAS}

Barroso, C.; Mello, G. N. de. O acesso da mulher ao ensino superior brasileiro. Cadernos de Pesquisa. São Paulo: Fundação Carlos Chagas, n. 15, 1975, p. 47.

BRASIL, Ministério da Educação. Lei de Diretrizes e Bases de Educação, n. 9.394/ 96. 20 dez. S. Paulo: Cortez - Ande, 1996.

FuRlani, L. M. T. A claridade da noite. Os alunos do ensino superior noturno. São Paulo: Cortez. 1998.

Hasembalg, C. O contexto das desigualdades raciais. In: Souza, J. (Org.) Multiculturalismo e racismo. Uma comparação Brasil-Estados Unidos. S.n.: Paralelo Quinze, 1996.

HENRIQUEZ, R. Gênero e raça no sistema de ensino. São Paulo: Garamond, Unesco, 2002.

Hoffmann, J. Avaliação mediadora, uma prática em construção da pré-escola à universidade. Porto Alegre: Mediação, 1993.

Lima, M. Estrutura ocupacional e grupos de gênero e cor no Brasil: um quadro atual. Rio de Janeiro: Centro de Estudos Afro-asiáticos, 1996.

Moenbecke, S. A pesquisa em educação e as desigualdades raciais no Brasil. Revista Brasileira de Política e Administração da Educação. v. 15, n. 1, jan./ jun., 1999. 
Passos, E. S. A resistência das estereótipos sexistas no ensino superior das regiões Norte e Nordeste. Universidade e Sociedade. Brasília, DF, v. 9, n. 20, 1999.

Pinheiro, A. A. C. A mulher na sociedade brasileira. Faculdade de Filosofia e Ciências Humanas da UFBA: Bahia, 1984.

Queiroz, D. M. Raça, gênero e educação superior. Salvador, 2001. Tese (Doutorado) - Universidade Federal da Bahia.

Rosenberg, C. Nota alta - o meganegócio da educação. Exame. São Paulo, n. 7, abr. 2002, p. 34-45.

Sampaio, H. M. S. O ensino superior no Brasil: o setor privado. São Paulo: Fapesp, 2000.

SANTANA, M. A mulher e o acesso à educação na RMS. v. 7, n. 2. Salvador: Bahia Análise e Dados, set. 1997. p. 129-134. Universidade Federal da Bahia. Perfil sócio-econômico e cultural dos estudantes de graduação da Universidade Federal da Bahia. Salvador, 1998.

VIEIRA, A. Programa “A Cor da Bahia”. Correio da Bahia. Salvador, jan. 2002. 